\title{
Adherence Evaluation of Vented Chest Seals in a Swine Skin model
}

Françoise Arnaud $\mathrm{PhD}^{1,2}$, Eric Maudlin-Jeronimo ${ }^{1}$, Adam Higgins ${ }^{1}$, Bijan Kheirabadi $\mathrm{PhD}^{3}$, Richard McCarron PhD ${ }^{1,2}$, Daniel Kennedy, RN, MBA ${ }^{4}$, Greggory Housler MScEng, $\mathrm{MBA}^{4}$

${ }^{1}$ Naval Medical Research Center, NeuroTrauma Department, Silver Spring, MD, 20910

${ }^{2}$ Department of Surgery, USUHS, National Naval Medical Center, Bethesda, MD 20889.

${ }^{3}$ U.S. Army Institute for Surgical Research (USAISR), Fort SAM Houston, TX, 78234

${ }^{4}$ U.S. Army Medical Materiel Agency (USAMMA), Fort Detrick, MD, 21702

Running title: Down selection of chest seals based on skin adhesion

Key Word: Pneumothorax, Trauma, Prehospital care, Evacuation

\section{Corresponding author:}

Françoise Arnaud, Ph.D.

Naval Medical Research Center

NeuroTrauma Department

503 Robert Grant Avenue

Silver Spring, MD 20910-7500

Tel: (301) 319-7687

Email: francoise.arnaud.ctr@mail.mil

Other authors

Eric Maudlin-Jeronimo: eric.m.maudlin-jeronimo.ctr@mail.mil

Adam Higgins: adamhiggins84@gmail.com

Bijan Kheirabadi: bijan.s.kheirabadi.civ@mail.mil

Richard McCarron: richard.m.mccarron.civ@ mail.mil

Daniel Kennedy: danokennedy@gmail.com

Greggory Housler: greggory.j.housler.civ@ mail.mil 


\section{Adherence Evaluation of Vented Chest Seals in a Swine Skin model}

\section{ABSTRACT}

Objectives: Perforation of the chest (open pneumothorax) with and without lung injury can cause air accumulation in the chest, positive intrapleural pressure and lead to tension pneumothorax if untreated. The performance of chest seals to prevent tension physiology depends partially on their ability to adhere to the skin and seal the chest wound. Novel non-occlusive vented chest seals were assessed for their adhesiveness on skin of live swine under normal and extreme environmental conditions to simulate austere battlefield conditions.

Methods: Chest seals were applied on the back of the swine on skin that was soiled by various environmental contaminants to represent battlefield situations. A peeling (horizontal rim peeling) and detachment and breaching (vertical pulling) techniques were used to quantify the adhesive performance of vented chest seals. Among eight initially selected vented seals, five (Bolin, Russell, Fast breathe, Hyfin and SAM) were further down-selected based on their superior adherence scores at ambient temperatures. The adherence of these seals was then assessed after approximately $17 \mathrm{~h}$ storage at extreme cold $\left(-19.5^{\circ} \mathrm{C}\right)$ and hot $\left(71.5^{\circ} \mathrm{C}\right)$ temperatures.

Results: Adherence scores for peeling (above 90\%) and detachment scores (less than 25\%) were comparable for four vented chest seals when tested at ambient temperature, except for the Bolin seal which had higher breaching. Under extreme storage temperatures, adherence peeling scores were comparable to those at ambient temperatures for four chest seals. Scores were significantly lower for the Bolin seal at extreme temperatures. This seal also had the highest detachment and breaching scores. In contrast, the Russell, Fast breathe, Hyfin and SAM seals showed similar ability to stay air tight without breaching after hot storage.

Conclusion: No significant difference was found in skin adherence of the five vented chest seals at ambient temperature and the four seals (Russell, Fast breathe, Hyfin and SAM) maintained superior adherence even after exposure to extreme temperatures compared to the Bolin. To select the most effective product from the 5 selected vented chest seals, further functional evaluation of the valve of these chest seals on a chest wound with the potential for tension in the pneumothorax or hemopneumothorax is warranted.

\section{Abbreviation List}

AAALAC: Association for Assessment and Accreditation for Laboratory Animal Care.

PTx: Tension pneumothorax

Wt: Total weight of the printed paper

Wa: paper weight of the attached printed section

Vd: Detachment volume (ml)

$\mathrm{Vb}$ : Breach volume (ml) 
Perforation of the chest with bullets or shrapnel can cause pneumothorax and lead to pulmonary collapse and changes in pulmonary tension. The positive intrathoracic pressure created in the chest cavity due to air accumulation, can prevent normal lung expansion, and lead to poor tissue oxygenation from compromised oxygen delivery to the alveoli. In recent conflicts, although open pneumothorax was not reported as a cause of mortality, if such an injury is not treated it can lead to tension pneumothorax, which is life-threatening, particularly when blood pools in the pleural cavity $[1,2]$. Therefore, coverage of the chest wound with chest seals before transport to definitive care is necessary to treat patients and prevent rise of intrapleural pressure and possible development of tension physiology.

Design of chest seals historically progressed from 3 sided chest seals, to non-vented (occlusive), to one way vented chest seals [1] [2]. Until recently, the Bolin Chest Seal (BCS, H\&H Associates, Ordinary, VA) and the Asherman Chest Seal, ACS TM (Teleflex, Morrisville, NC) were the only two vented chest seals available for warfighters [3]. Recently, novel chest seals have been developed with a different type, shape, material, and valves to enhance the evacuation of air and possibly blood from the pleural cavity. Furthermore, such chest seals were intended to avoid obstruction of the valve by external environmental artifacts or blood clots. Among other properties, adherence of the seal to the skin is a key element to ensure complete wound closure necessary to ensure control of pneumothorax and restore pulmonary function. In June 2013, the Tactical Combat Casualty Care (TCCC) committee recommended the use of vented seals for improved pulmonary function on open pneumothorax as a result of recent publications showing that non-vented seals could potentially lead to life threatening conditions $[2,4]$. Indeed, the use of the nonvented chest seals could lead to tension (PTx), hypoxemia, and increase morbidity and mortality. Therefore, a down-selection of vented seals based on adhesion properties was necessary prior to further testing of physiological performance, as well as before final incorporation of the best products to Soldier's individual first aid kits (IFAK).

This study describes horizontal peeling and vertical pulling (detachment) techniques to quantify the adhesion scores of each selected chest seal on the skin of live swine [3].

\section{MATERIALS and METHODS}

\section{Chest seals}

The following eight (8) vented chest seals were tested in this study: Asherman (Asherman Chest Seal) from Teleflex, Morrisville, NC; Bolin (Bolin Chest Seal \# 6510-01-549-0939) and Bolin Chest Seal XL from H\&H Associates, Ordinary, VA; Hyfin (HyFin Vent \#10-0029) from North American Rescue, Greer, SC; Fast Breathe (Fast Breathe Thoracic seal \#FT078FTS) from JBC Corp, Virginia Beach, VA; Sentinel (Sentinel Chest Seal) from Combat Medical Systems, Harrisburg, NC; Russell (Russell Chest Seal) from Tactical Medical Solutions, Anderson, SC; SAM (SAM Chest Seal with Valve \#1216-01104) from BoundTree Medical, Chicago, IL. Some seals from the same company were made with identical adhesive material (hydrogel) but differed in size and/or with/without vents). The determination of the chest seal surface area allowed the ranking of seals by size [small $\left(<160 \mathrm{~cm}^{2}\right)$, medium $\left(230-300 \mathrm{~cm}^{2}\right)$, large $\left(300-350 \mathrm{~cm}^{2}\right)$ and extra large $\left(>350 \mathrm{~cm}^{2}\right)$ ]. Regardless of the size, no changes were made to the seals to fit the application area on the animal's back. Illustration of the vented chest seals (Figure 1S) is provided in the supplemental material section. Each seal is composed of three main layers: a) the backing of the seal that needs to be removed before application, b) the layer with adhesive material (polymeric hydrogel), and c) the cover and the venting valve (vented chest seals only). These different parts are illustrated in Figure $2 \mathrm{~S}$ (supplemental material). 


\section{Storage/exposure testing conditions}

Chest seals were kept at ambient temperature $\left[20-22^{\circ} \mathrm{C}\right]$ (temperature controlled laboratory), or stored at extreme cold $\left[-17^{\circ}\right.$ to $\left.19^{\circ} \mathrm{C} ;-19.5 \pm 1.3^{\circ} \mathrm{C}\right]$ (non-defrost laboratory freezer) temperatures or extremely hot $\left[70^{\circ}\right.$ to $72^{\circ} \mathrm{C} ; 71.5 \pm 2.0^{\circ} \mathrm{C}$ ] (VWR 1310E, VWR Radnor, PA) (non-defrost freezer) temperatures for an average of $17.7 \pm 1.5$ hours. Temperature was monitored using a iLog digital thermometer (Cryopak, Buchanan, VA) for cold temperature and a Bat 9 digital thermometer (PhysiTemp, Clifton, NJ) for the hot temperature. These different temperature storage conditions was intended to simulate storage of the seal in a service member's (e.g., a medic) backpack during a mission in austere environments. These conditions were previously used in a USAMRMC pilot study with 16 hour exposure of the seals at these colder and hotter temperatures [Personal communication: U.S. ARMY MEDICAL RESEARCH \& MATERIEL COMMAND TEST BRANCH U. Test and Evaluation of Chest Seals - Adhesion testing. Internal report. In: USAMRMC, editor. June 2012]. Noteworthy, this study was designed to focus primarily on the ability of the seals to adhere to the skin of live swine following storage at extreme temperatures and not the adherence performance of the seals being extremely cold or hot when applied on the skin. Therefore, after the seal packages were removed from their storage conditions (either cold or hot locations), the seals were allowed to equilibrate at ambient temperature for 15 to 40 minutes before being applied to swine skin. In this way, all the seals were assessed under similar conditions when applied on the skin of a normothermic pig.

To simulate combat environmental conditions and potential contaminants (e.g., material and body fluid) covering the skin of injured personnel, the seals were tested under the following soiling sub-conditions: clean dry skin (none), skin covered with swine blood (blood), skin covered with dry sand (sand), and skin covered with blood and dry sand (blood and sand). In addition, chest seals were tested on unshaved (with hair) skin or shaved skin of swine. High wind, sand, rain, hot and cold weather often relate to challenges in extreme environment [5]. Experimental soiling conditions will never exactly replicate the environmental conditions experienced in deployment zones; however, the material used to simulate soiling was deemed representative for most situations encountered by warriors.

\section{Ex Vivo Experiment}

The animal study protocol (KO12-06) was reviewed and approved by the Walter Reed Army Institute of Research/Naval Medical Research Center Institutional Animal Care and Use Committee in compliance with all applicable Federal regulations governing the protection of animals in research. The animal facility is accredited by the Association for Assessment and Accreditation for Laboratory Animal Care International (AAALAC).

Swine skin may differ from human skin regarding its thickness, but based on previous pre-clinical studies performed with chest seals, it offers an appropriate model for adhesion and a surface sufficiently wide enough to accommodate the size of the seal [3] [4] [6] [7].

\section{Animal skin preparation}

A large animal was needed to examine the adhesion of the chest seals and swine is an appropriate size animal. Yorkshire swine (average weight $32.8 \pm 2.7 \mathrm{~kg}$ ) were obtained from Animal Biotech Industries, (Danboro, PA). The animals were fasted for approximately 12 hours prior to the procedure with water provided ad libitum. Induction of anesthesia was initiated with an intramuscular injection of ketamine hydrochloride $(33 \mathrm{mg} / \mathrm{kg})$ and atropine sulfate $(0.05 \mathrm{mg} / \mathrm{kg})$, followed by mask ventilation with isoflurane inhalant (1-5\%), and endotracheal intubation in the surgical pre-op area. After intubation, the animals were transported to the operating room, and placed in a dorsal recumbent position on the operating table. Anesthesia was maintained with isoflurane (1-3\%) delivered by medical air through an anesthesia machine (Apollo, Draeger Medical, Inc). All animals received an intravenous maintenance fluid infusion of normal 
saline at $2.5 \mathrm{~mL} / \mathrm{kg} / \mathrm{hr}$ to balance fluid loss from anesthesia. Prior to surgical procedures, an intramuscular injection of buprenorphine $(0.01 \mathrm{mg} / \mathrm{kg})$ was administered for pre-emptive analgesia. A catheter was placed in the carotid artery for monitoring blood pressure and another catheter was placed in jugular vein for blood sampling. The animals were transferred to the chest seal testing protocol when they had a stable blood pressure, heart rate, and near $100 \% \mathrm{SpO}_{2}$, and were turned to sternal recumbent position. Before applying the chest seal on the skin, the area corresponding to the seal perimeter was marked as a pre-set area. Peripheral blood was drawn $(10 \mathrm{ml})$ from the animal and smeared immediately on the skin to simulate the required soiling condition. Volumes of blood were standardized to $5 \mathrm{~mL}$ per treatment site to cover the preset skin area. Blood was evenly smeared across the area with the gauze pad included in the chest seal packaging before the seal application. This provided sufficient coverage of the pre-set area with blood to ensure performance testing. Approximately $1.5 \mathrm{~cm}^{3}$ of fine grit sand was used (roughly measured to fill up a $2 \mathrm{~mL}$ Eppendorf tube) was dispersed over the testing area using a woven mesh 4" x 4" gauze pad as a sieve. This procedure provided a controlled method for uniform distribution of sand grains (Fine Sand, Sakrete; 0.1-0.3 mm bead diameter) on the pre-set skin surface. After testing chest seals under each subcondition, the skin was cleaned with water, gauzes, and alcohol pads to remove the remaining residues of adhesive as well as to prepare the skin for next seal test.

\section{Chest Seal Adherence Measurement}

Manual methodologies for measuring peeling the chest seals off swines' skin and pulling the seal vertically by the central vent to assess detachment were previously described and empirically scored [3]. This method was modified to alleviate the investigator biases and to obtain quantitative measurements of detachment as follows:

Peeling Technique (Horizontal rim peeling): The seal was applied (one seal at a time and a new seal for each test condition) on the lower back or the upper back between the shoulder blades of the swine. This represented a flat area of the swine anatomy which had coarse hairs. After the seal application, the complete coverage and adherence on the surface area was checked. Then, the rim of the seal was gently manually rubbed to identify the unbound portion of the seal. If the seal did not lift from the skin initially no additional peeling was pursued. If the seal started lifting (peeling off), this motion was gently continued inward until no more separation was noticed. The contour of the area that peeled off was marked with a black marker. The seal was then removed from the animal and a picture of the seal was taken, printed, and the paper was weighed (total weight (Wt). The print was cut following the external ridge of the marked border on the seal and the remaining paper was weighed (Wa). The percent of the seal that adhered was then calculated as follows:

Adherence for horizontal peeling score $(\%)=(\mathrm{Wa} / \mathrm{Wt}) \times 100$

Detachment Technique (Vertical pulling): The device (Fig. 1) consisted of a syringe system (A) with the plunger attached by industrial strength Velcro to a plate itself in contact with the chest seal; the Luer lock end of the syringe was connected via pressure tubing to another syringe (B), free to displace water between the two syringes. This system was secured to an adjustable railing mechanism that allows motions to adjust freely the position of the syringe laterally and vertically along the longitudinal axis of the animal. When the water from syringe B was manually aspirated, the liquid transmitted the force to syringe A to lift up with the attached seal. The displacement of the liquid in the syringe was a quantitative measure of the detachment of the seal from the skin. The maximum syringe displacement obtained with this system was twenty (20) $\mathrm{ml}$. Several possibilities could occur: if the air tight seal remained firmly adhered to the skin, the pulling motion was stopped and granted a score of 20. The first sign of the seal detaching from the skin, forming a focal detachment or "blister" and the remaining air tight, was recorded as "Detachment volume" $(\mathrm{Vd}, \mathrm{ml})$. As pulling continued until a breach between the seal and the skin was observed, breaking the airtightness, such opening renders the seal non-functional this was recorded as "Breach volume" (Vb, ml). Breaching was also reported as incidence of seal failure. 
The adherence for vertical pulling was calculated with 2 scores as follows:

Detachment $(\%)=\mathrm{Vd} / 20 \times 100$

Breaching $(\%)=100-\mathrm{Vb} / 20 \times 100$

In addition to the peeling and detachment tests, tertiary tests involving the ease or difficulty in removing the backing of the seal, along with placing the seal on and removing it from the skin were also recorded.

\section{Statistical Analysis}

Chest seals were tested by batches of 5 vented seals that were randomly selected between brand, temperature, and treatment conditions to best accommodate the time pace of the testing regimen: each batch took approximately $40 \mathrm{~min}$ to be assessed for both peeling and pulling. After the 5 seals were tested, another batch of 5 seals was removed from the storage. Approximately, 3 batches, each containing 5 seals were tested per pig (i.e. an average of 15 chest seals per pig for the experimental day). An average of three (3) replicates of each sub-condition and temperature were tested per seal, and a score was obtained for each of the different soiling conditions, under each unshaved and shaved skin status conditions, and for peeling and detachment. A final score was calculated by averaging each score (from the soiling, skin status, and temperature conditions) and was used to rank the overall adherence performance of the chest seals. A threeway Analysis of Variance (ANOVA) was used to compare the resulting scores among temperature, skin status, and soiling conditions for each product at a significance level of 95\%. Tukey's method was used to adjust p-value for all paired wised post-hoc analyses for product comparison. The Statistical Package for the Social Sciences (SPSS; IBM Corporation, NY) software statistical package was used for all analyses.

\section{RESULTS}

From the 8 vented seals that were tested at ambient temperature without exposure to extreme temperature, 3 were excluded: the Sentinel and the Asherman because of their poor initial performance $(<65 \%$ for the horizontal peeling and $<50 \%$ for the vertical pulling; $<55 \%$ overall adherence score), and the extra-large Bolin seal (Bolin XL with a surface area $>300 \mathrm{~cm}^{2}$ ) that had a score $<60 \%$ for the vertical pulling. In addition, the backing of the Bolin XL seal did not cover the entire adhesive surface of the seal in the proximity of the vent. This caused the gauze pad included in the package to stick to the adhesive and would often tear and obstruct the vent when removed. Impracticality of the large size, poor packaging, and low score yielded to the elimination of the Bolin XL seal, but the smaller sized Bolin seal was retained for study. The results of all vented seals are included in the supplemental material as well as those for nonvented seals. Thus, this left 5 vented seals for further testing for extreme storage temperature: the SAM, Hyfin, Russell, Fast Breathe, and Bolin Chest Seals (Table 1).

\section{Horizontal Peeling Measurement results}

Results for the horizontal scores are summarized in Table 2. Most of the chest seals scored above $80 \%$ for adherence to clean and soiled skin, except for the Bolin chest seal. The overall horizontal peeling score of the seals after storage at extreme hot temperatures was slightly reduced but did not significantly differ from the ambient or cold storage. In general, the adherence score was higher on shaved skin $(\mathrm{p}<0.05)$ except for the Bolin seal after storage in hot temperatures, as this seal did not adhere well on shaved clean skin, which reduced its overall peeling score $(\mathrm{p}<0.001)$. The other seals exhibited consistent scores regardless of storage temperature (e.g. Russel ranked second at ambient, cold, and hot; Fast Breathe ranked lower). Compared to the clean skin, the addition of soiling material reduced the adherence score but not 
significantly. The rank order from the highest to lowest score was: Hyfin $=$ Russell $=$ SAM $>$ Fast Breathe $=$ Bolin Chest Seals.

\section{Vertical Pulling results}

Pulling results for detachment scores (without breaching) for all conditions are summarized in Table 3. Overall, there were differences among seals and among conditions ( $p<0.05$, ANOVA), but each seal rank was similar within the temperature group (e.g. Russel ranked first or second and the Bolin ranked last). However, detachment scores with Bolin were very variable and were significantly higher than other seals $(\mathrm{p}<0.05)$. Fast Breathe fared higher detachment after ambient and cold temperatures on unshaved skin than after hot temperature exposure or on shaved skin. Soiling conditions with blood plus sand seemed more challenging to maintain good adherence. Not all seals exhibited breaching (complete separation of the seal and skin) (Table 4). Breaching occurred infrequently as most of the seal's integrity remained intact (air tight) during the experiments and appeared to be unrelated to the detachment score. There was a high variability with respect to skin treatment conditions. Overall, the seals had a low breaching incidence but the Bolin seal had the highest incidence of breaching. Breaching was less likely to happen under hot conditions. Seals with the lowest failure ranked as Russel $=\mathrm{SAM}=$ Hyfin $=$ Fast Breathe $>>$ Bolin Chest Seals.

We deemed important to report the following general observations that were made while using these 5 seals. Packaging: Multiple folded seals such as the Russell Chest Seal contained large creases, which prevented smooth, uniform adhesion when applied to the skin. In turn, this feature formed a "blister" that may have compromised the integrity of the seal if not applied properly, thus increasing the risk for seal failure. This was more evident when the cover was rigid. Material: a) The original Russell Chest Seal had a tendency to stretch and distort during backing removal. The backing often tore due to its brittle material and strong binding to the adhesive; this was resolved in the new Russel seal. Vent: The Fast Breathe Thoracic Seal contains a circular vent with a raised plastic cover that can be easily unfastened from its base with only moderate force letting fine debris settle on top of the valve. These are criteria underlining practical aspects of the seal other than adherence that could be critical in austere environment. A summarized version of the general properties of the 5 vented seals is listed in Table 4S as supplemental material.

\section{DISCUSSION}

Adherence performance of chest seals was initially measured in order to down select the most efficient seals prior to future physiological function evaluation. This project was originally initiated by testing 17 chest seals stored at ambient temperature including occlusive non-vented seals (see supplemental material). Upon recommendations of the Tactical Combat Casualty Care (TCCC) committee, only vented seals were selected for improved pulmonary function on open pneumothorax [2, 4] therefore, the selection was limited to 8 vented chest seals (Asherman; Bolin and Bolin XL; Sentinel; Russell; Fast Breathe; Hyfin and SAM). Overall, based on the scores of these 8 seals from horizontal (less than 65\%) and vertical pulling (more than 50\%) that were first tested at ambient temperature (Table 1S and 2S) only 5 seals (Bolin; Russell; Fast Breathe; Hyfin and SAM) were selected for further testing at extreme storage temperatures. The scores (horizontal peeling), the incidence of detachment, and eventually breaching, were measured under different environmental conditions and adherence scores for peeling (above 90\%) and detachment (less than 25\%), and these scores were comparable for the Russell, Fast breathe, Hyfin and SAM chest seals when tested at ambient temperature. After exposure to extreme temperatures, the 4 vented seals showed similar ability to adhere to skin, remained intact, and attached to the skin with an overall effective adhesion score above $80 \%$. One chest seal, Bolin, showed poor performance with the highest breaching score. 
Storage of the 5 selected vented chest seals stored at extreme temperatures had little or no effect on the adherence of the seals assessed by horizontal (peeling) or vertical pulling (detachment or breach) methods. Chest seals adherence against horizontal peeling was very similar among these seals and skin conditions. The capability to detach varied according to seal type and skin soiling conditions. This test illustrated the risk for the seal to lose its integrity which was expressed by breaching, an indication for failure of the seals. The two products without breaching were the Russel and SAM chest seals under all conditions; although detachments occurred, they never resulted in failure. These seals showed good adherence to peeling as well. The Bolin chest seals with a low adherence score had a lower limit for detachment and eventually showed breaching.

Regardless of the storage temperature, we observed that swine coarse hair occasionally caused the hydrogel to stick to the hair rather than to the swine skin underneath. Although not statistically significant, this observation was particularly noticeable with the Bolin chest seal and it may be responsible for the high variability in all responses exhibited by this seal. The reason for this is unclear but given that this seal was slightly more rigid than the other chest seals, the Bolin seal may have conformed less to a coarse surface. The Russell, SAM, and Fast Breathe seals were very flexible and conformed better to the skin. We observed some detachment at the crease of folded seals (particularly with the original Russel and new Fast Breathe seals) but this did not result in breaching. In general, soiling with blood plus sand was effective to alter adherence compared to clean skin. The difference of vertical pulling scores between seals may be due to the elasticity of the seal, the size and geometry, and the air trapped below the vent. The hydrogel glue serving as an adhesive provides some elasticity and the cover of the seal could also exhibit some plasticity. For example, the Bolin seal is round in geometry, has a hard cover, and contains a thick hydrogel layer. In contrast, the Russell seal is rectangular in geometry, has a malleable plastic cover, and a thin film of adhesive, and all these characteristics which may explain the higher score. A quick inspection of the vents or valves for possible obstruction did not reveal abnormality or was not a source of weakness due to extreme temperature exposure.

Adherence: Storage at high temperature reduced detachment and breaching particularly for the Russel and Fast Breathe seals. For example, we noticed in a few occasions the tendency of the adhesive material to "melt" and the glue retracted from the rim of the seal as for the Fast Breathe and SAM chest seals. This was particularly noticeable for the seals with a thick hydrogel layer (e.g., Fast Breathe and SAM); compared to seals such as the Russell with a thinner hydrogel layer. This may have caused the Bolin's cover to separate from the Bolin seal (as was true for a few cases of full separation) but still the contact between the gel and the skin was maintained. Additionally, traces of glue remained on the skin following removal which was very difficult to completely clean, particularly for the SAM, Hyfin, and Fast Breath chest seals, after high temperature exposure.

Some of the seals were modified by the manufacturers in the interim of the study: a) Backing: The removal of the original Russell Chest Seal covering sheath was extremely difficult regardless of the temperature to the point that it broke or caused the seal to stretch and distort, thus making it difficult to apply to the skin. The backing of the new Russell seal was flexible and completely prevented this removal resistance, and allowed for an easy application of the seal. b) Pulling flaps: they are made for easy removal of the backing and applying/removal of seals. Having one flap (Bolin, Fast Breathe and Hyfin) the application of the seal may be more challenging in rough environment, whereas having 2 flaps made the application of the seal less challenging (SAM and the new Fast Breathe). The original Russell did not have a flap and both sides were held as it was applied. c) Adhesive backing: we observed that when exposed to hot temperatures the plastic backing of the original Bolin chest seal had the tendency to detach from the adhesive. This phenomenon was amplified with the new seal during the peeling and pulling test the adhesive remained attached to the skin but the backing completely separated only to be held in place on the skin by the vent. The backing of the new Fast Breathe was changed from fabric to thin plastic and such a change did not seem to affect either the peeling or detachment test results. 
A tertiary but important endpoint was the removal of the seal from the skin to simulate hospital care. Removal of seals from shaved skin appeared a bit more difficult than unshaved skin, consistent with the fact that the scores were higher on shaved skin. Removal of the SAM seal was extremely difficult after exposure to either hot or cold temperatures, regardless of the skin state conditions; removal of the Hyfin seal was also challenging. Supinsky and colleagues evaluated several chest seals on human volunteer subjects and reported significant skin irritation as we noticed upon removal of the SAM and Hyfin seals as a negative side effect [8]. Adherence seemed to increase after exposure to hot temperature for Hyfin and the new Fast Breathe seal. Removal of the original Russell seal was almost impossible without tearing the whole seal because of the absence of the flaps.

In Supinsky's study, the seal's performance in conjunction with physical activity to cause sweating (ability of the seal to maintain contact with the wet skin) was similar to our peeling test [8]. In addition, these investigators examined the reseal ability of the products; they found that the Asherman and Sentinel seals were poor for resealing, similar to our down selection findings. In contrast, among vented seals that they evaluated (Bolin, Russell and SAM seals), the Bolin seal was a top adhesive performer, whereas the Russell seal exhibited opposite results. In this case, adhesion of the Bolin chest seal to human skin may differ from swine skin. We noticed a problem related to longer and coarser swine hair that may have attributed to different adhesion strength as compared to finer human hair. Similar to our findings, they reported difficulties in the application of the Russell's seal due to the breaking of the backing. This difficulty was similar to our test with the original Russel seal with which we described curling and folding; but the new adhesive on the new Russel eliminated this problem. This initial complication has created some bias in the assay quantitation; the area that did not attach initially was not considered in the calculation leading to a higher rating for the Russell than the Bolin seal; this may have increased our score and accounting for the difference between Suprinki's study and our results. Furthermore, the "burping/blistering" rate also illustrated that the previous Russell seal could not be resealed to the skin and such a problem is not the case with the new Russell seal. Wayne conducted a study with the Asherman, Bolin, Halo and SAM seals [6] are reported that the Asherman and Bolin seals lost adhesion and failed to remain on the skin after a typical period of wear; in contrast SAM and Halo demonstrated higher adhesion values. Kotora et al. conducted a physiological testing of chest seals in a pneumothorax swine model [7]. They found that the Hyfin, Sentinel and SAM (all vented seals) seals were similarly efficacious in preventing tension pneumothorax. Of these three vented seals, the Sentinel seal was deleted in our downselection study because of poor initial adhesion performance; it is unknown if the Sentinel seals used by Kotara and colleagues were the ones we used, or whether they were a newer upgrade of the same seals.

\section{Limitations}

1) There were no positive controls in this study, however now that chest seals with strong adhesiveness scores have been identified (e.g. New Russell, SAM) they could serve as reference for future studies.

2) More repeated tests per seal would have increased the statistical power. Only one seal per condition was tested for the initial down selection, but nonetheless, the numerous different skin treatment conditions served as secondary differentiation among the effectiveness of performance of the chest seals.

3) Some seals were modified in the interim of the study, which was out of our control. However, according to the manufacturer information, the changes had no effect on adhesive properties of the seals that was the primary goal of our study. Therefore, we deemed appropriate to combine the results of these seals.

4) The methods for the adhesiveness evaluation were designed to represent horizontal peeling and vertical pulling, however, other directional pulling of the seals could have been included.

5) The applied seals were not held in place for a long period of time as was done in Supinsky's report. Instead, our seals were applied and tested immediately following application, and therefore, it is unclear how much the adhesion would change after prolonged application. 
Five vented FDA cleared (or near clearance at the time of testing) chest seals were down selected and assessed after storage at extreme temperatures for their adherence on swine skin using horizontal peeling and vertical pulling methods. Four of the five vented chest seals (Russell, Fast breathe, Hyfin and SAM) with different valve/vent types adhered well and sustained adhesive function after exposure to extreme environmental conditions without significant differences in adherence, thus assuring the best integrity of the product. In contrast, Bolin, the fifth chest seal, had a lower performance than the other four seals. These results suggest that other qualitative non-adhesive characteristics should be considered for a more specific down-selection of chest seals. Therefore, a follow-up future functional evaluation of these chest seals based on their vent function in preventing tension physiology is warranted.

\section{REFERENCES}

[1] McPherson JJ, Feigin DS, Bellamy RF. Prevalence of tension pneumothorax in fatally wounded combat casualties. The Journal of trauma. 2006;60:573-8.

[2] Butler FK, Dubose JJ, Otten EJ, Bennett DR, Gerhardt RT, Kheirabadi BS, et al. Management of Open Pneumothorax in Tactical Combat Casualty Care: TCCC Guidelines Change 13-02. Journal of special operations medicine : a peer reviewed journal for SOF medical professionals. 2013;13:81-6.

[3] Arnaud F, Tomori T, Teranishi K, Yun J, McCarron R, Mahon R. Evaluation of chest seal performance in a swine model: comparison of Asherman vs. Bolin seal. Injury. 2008;39:1082-8.

[4] Kheirabadi BS, Terrazas IB, Koller A, Allen PB, Klemcke HG, Convertino VA, et al. Vented versus unvented chest seals for treatment of pneumothorax and prevention of tension pneumothorax in a swine model. The journal of trauma and acute care surgery. 2013;75:150-6.

[5] DelaCruz J. Maintenance in extreme environments \& deployments.

http://www.sae.org/events/dod/presentations/2003jerrydelacruzee1.pdf: Armed Forces Service Operation; 2003.

[6] Wayne M. Comparison of devices for emergency treatment of open pneumothorax. Prehosp Emerg Care. 2012;16:173.

[7] Kotora JG, Jr., Henao J, Littlejohn LF, Kircher S. Vented chest seals for prevention of tension pneumothorax in a communicating pneumothorax. The Journal of emergency medicine. 2013;45:686-94. [8] Supinsky DP NM, Gerhart RT. Chest seal adherence on human test subjects: A prospective study. Internal report USAMMA. In: USAMMA, editor.January 2014. 


\title{
Photographs for reviewers
}

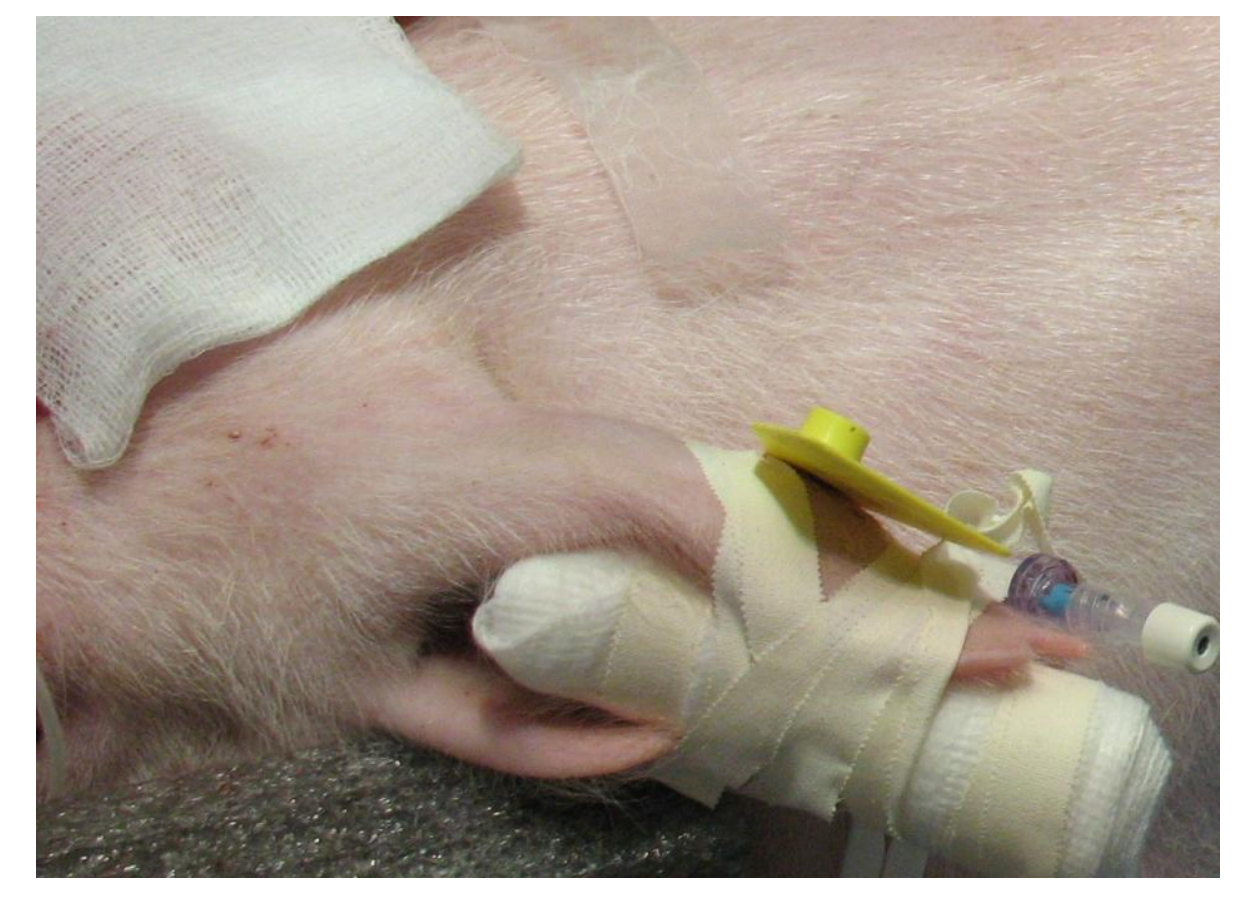

Fresh pig skin

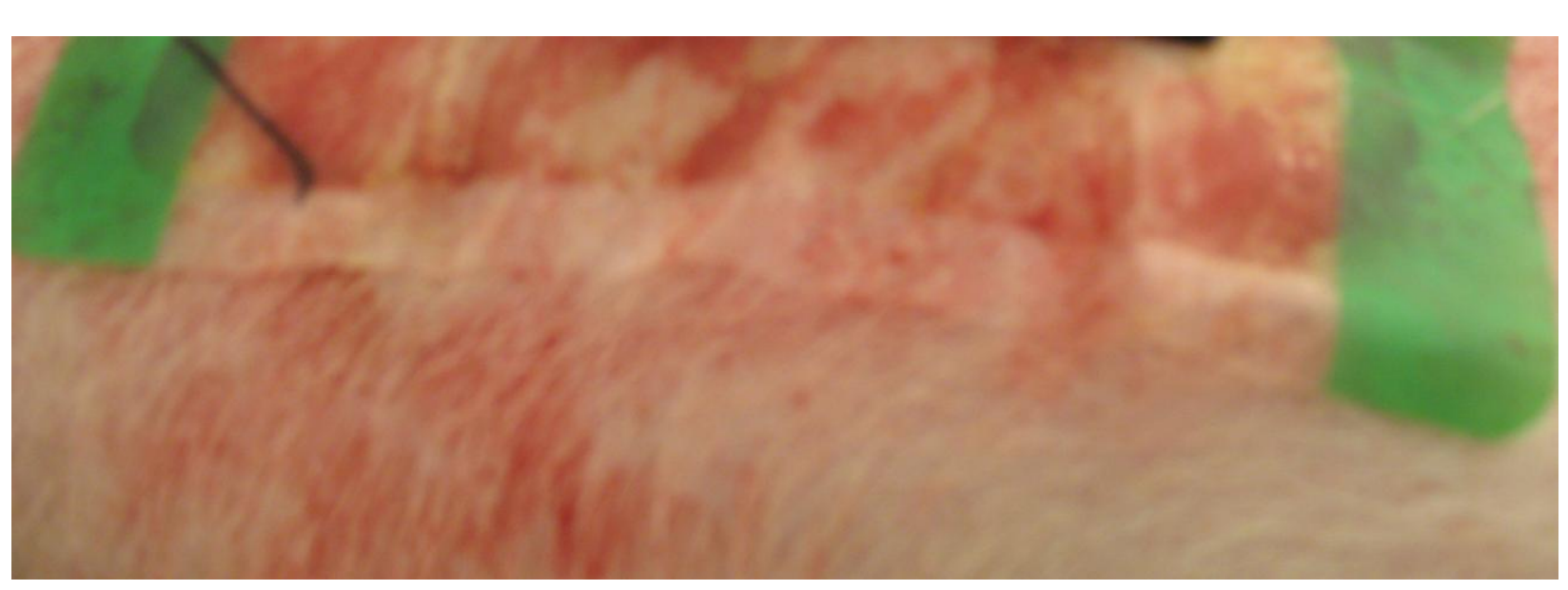

Blood soiled skin with chest seal

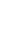

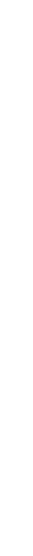

\author{
(a)
}

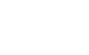

\section{s}




\section{TABLES}

\begin{tabular}{|c|c|c|c|c|c|c|c|c|c|c|c|}
\hline & Product & Manufacturer & Distributer & Part Number & catalog \# & $\begin{array}{c}\text { Price as of } \\
02-14-14\end{array}$ & Shelf live & $\begin{array}{c}\text { FDA } \\
\text { Clearance }\end{array}$ & Original seal & $\begin{array}{c}\text { Current New } \\
\text { Standard }\end{array}$ & $\begin{array}{c}\text { Storage } \\
\text { specification }\end{array}$ \\
\hline 1 & $\begin{array}{l}\text { Bolin chest seal } \\
\text { (BCS) }\end{array}$ & $\mathrm{H} \& \mathrm{H}$ & $\mathrm{H} \& \mathrm{H}$ & $\begin{array}{c}\text { NSN 6510-01- } \\
549-0939\end{array}$ & $549-0939$ & $\$ 14.14$ & 3 Years & Yes & $\begin{array}{l}3 \text { valves in } \\
\text { triangle }\end{array}$ & 3 valves aligned & None \\
\hline 2 & $\begin{array}{c}\text { Russell chest seal } \\
\text { (RCS) }\end{array}$ & $\begin{array}{l}\text { Promethius } \\
\text { Medical LTD. }\end{array}$ & Tactical Medical & $\begin{array}{c}\text { 64-1-99-490- } \\
5137\end{array}$ & RCS & $\$ 18.95$ & 3 Years & Yes & Sticky backing & with New backing & $0-32 \mathrm{C}$ \\
\hline 3 & $\begin{array}{c}\text { Fast Breathe Thoracic } \\
\text { seal (FTS) }\end{array}$ & FastTrack & FastTrack & FT078FTS & FT078FTS & $\$ 15$ & 4 Years & Pending & fabric cover & $\begin{array}{l}\text { Folded with new } \\
\text { plastic Cover }\end{array}$ & None \\
\hline 4 & $\begin{array}{c}\text { HyFin Vent (HCS } \\
\text { vent) }\end{array}$ & $\begin{array}{l}\text { North American } \\
\text { Rescue }\end{array}$ & $\begin{array}{l}\text { North American } \\
\text { Rescue }\end{array}$ & $10-0029$ & $10-0029$ & $\$ 13.48$ & 5 Years & Yes & 1 Channel & $\begin{array}{l}\text { current } 1 \text { channel } \\
\text { valve may } \\
\text { develop to } \\
\text { Multiple channel }\end{array}$ & None \\
\hline 5 & SAM chest seal with & SAM Medical & Bound Tree & CS062010 & $1216-01104$ & $\$ 21.51$ & $3 Y$ going to & Yes & & No & None \\
\hline
\end{tabular}

Table 1. List of the 5 vented chest seals and product characteristics with their modification and updated version used in this study. The information provided is as of 14 February 2014. 


\section{TABLES}

\begin{tabular}{|c|c|c|c|c|c|c|c|c|c|}
\hline \multirow{2}{*}{$\begin{array}{c}\text { Horizontal Peeling (\%) } \\
\text { Ambient temperature }\end{array}$} & \multicolumn{4}{|c|}{ Unshaved skin } & \multicolumn{4}{|c|}{ Shaved skin } & \multirow{2}{*}{$\begin{array}{l}\text { Horizontal } \\
\text { adherence } \\
\text { score }\end{array}$} \\
\hline & $\begin{array}{c}\text { Clean } \\
\text { skin }\end{array}$ & Sand & Blood & $\begin{array}{c}\text { Blood + } \\
\text { Sand }\end{array}$ & Clean skin & Sand & Blood & $\begin{array}{c}\text { Blood + } \\
\text { Sand }\end{array}$ & \\
\hline Bolin chest seal $^{\mathrm{TM}}$ & 100 & 98 & 95 & 96 & 100 & 100 & 97 & 98 & 98 \\
\hline 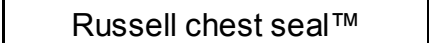 & 97 & 96 & 96 & 99 & 100 & 100 & 100 & 100 & 98 \\
\hline FAST Breathe Thoracic seal® & 90 & 88 & 82 & 82 & 99 & 95 & 88 & 88 & 89 \\
\hline HyFin Vent ${ }^{\circledR}$ & 100 & 100 & 95 & 98 & 100 & 100 & 100 & 100 & 99 \\
\hline SAM chest seal with valve $\AA$ & 99 & 100 & 100 & 87 & 100 & 100 & 100 & 100 & 98 \\
\hline
\end{tabular}

\begin{tabular}{|c|c|c|c|c|c|c|c|}
\hline Horizontal Peeling (\%) & \multicolumn{3}{|c|}{ Unshaved skin } & \multicolumn{3}{|c|}{ Shaved skin } & \multirow{2}{*}{$\begin{array}{l}\text { Horizontal } \\
\text { adherence } \\
\text { score }\end{array}$} \\
\hline$-19.5 \pm 1.3^{\circ} \mathrm{C}$ & $\begin{array}{l}\text { Clean } \\
\text { skin }\end{array}$ & Blood & $\begin{array}{c}\text { Blood + } \\
\text { Sand }\end{array}$ & Clean skin & Blood & $\begin{array}{c}\text { Blood + } \\
\text { Sand }\end{array}$ & \\
\hline 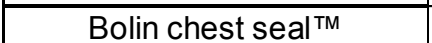 & 90 & 86 & 82 & 97 & 96 & 90 & 90 \\
\hline Russell chest seal ${ }^{\mathrm{TM}}$ & 94 & 96 & 90 & 97 & 96 & 98 & 95 \\
\hline FAST Breathe Thoracic seal® & 92 & 84 & 78 & 95 & 96 & 88 & 89 \\
\hline HyFin Vent® & 98 & 92 & 87 & 97 & 99 & 98 & 95 \\
\hline SAM chest seal with valve ${ }^{\circledR}$ & 97 & 97 & 87 & 99 & 98 & 90 & 94 \\
\hline
\end{tabular}

\begin{tabular}{|c|c|c|c|c|c|c|c|}
\hline Horizontal Peeling (\%) & \multicolumn{3}{|c|}{ Unshaved Skin } & \multicolumn{3}{|c|}{ Shaved Skin } & \multirow{2}{*}{$\begin{array}{l}\text { Horizontal } \\
\text { adherence } \\
\text { score }\end{array}$} \\
\hline $71.5 \pm 2.0^{\circ} \mathrm{C}$ & $\begin{array}{c}\text { Clean } \\
\text { skin }\end{array}$ & Blood & $\begin{array}{c}\text { Blood + } \\
\text { Sand }\end{array}$ & Clean skin & Blood & $\begin{array}{c}\text { Blood + } \\
\text { Sand }\end{array}$ & \\
\hline Bolin chest seal $^{\mathrm{TM}}$ & 87 & 92 & 77 & $47^{*}$ & 91 & 79 & 79 \\
\hline Russell chest seal ${ }^{\mathrm{TM}}$ & 98 & 97 & 96 & 88 & 99 & 92 & 95 \\
\hline FAST Breathe Thoracic seal® & 89 & 80 & 84 & 95 & 99 & 81 & 88 \\
\hline HyFin Vent $\circledast$ & 98 & 96 & 91 & 97 & 99 & 96 & 96 \\
\hline SAM chest seal with valve ${ }^{\circledR}$ & 96 & 95 & 94 & 98 & 97 & 96 & 96 \\
\hline
\end{tabular}

Table 2: Horizontal peeling results at ambient, $-19.5{ }^{\circ} \mathrm{C}$ and $71.5^{\circ} \mathrm{C}$ temperatures for the 5 vented chest seals tested under various soiled skin conditions. The horizontal adherence score is the average of all scores. ${ }^{*} \mathrm{p}<0.01$. 
TABLES

\begin{tabular}{|c|c|c|c|c|c|c|c|c|c|}
\hline \multirow{3}{*}{$\begin{array}{l}\text { Vertical Pulling (\%) } \\
\text { Ambient temperature }\end{array}$} & \multicolumn{9}{|c|}{ Detachment } \\
\hline & \multicolumn{4}{|c|}{ Unshaved skin } & \multicolumn{4}{|c|}{ Shaved skin } & \multirow{2}{*}{$\begin{array}{c}\text { detachment } \\
\text { score }\end{array}$} \\
\hline & $\begin{array}{l}\text { Clean } \\
\text { skin }\end{array}$ & Sand & Blood & $\begin{array}{c}\text { Blood + } \\
\text { Sand }\end{array}$ & Clean skin & Sand & Blood & $\begin{array}{l}\text { Blood + } \\
\text { Sand }\end{array}$ & \\
\hline Bolin chest seal $^{\mathrm{TM}}$ & 70 & 70 & 70 & 70 & - & 50 & - & 35 & 46 \\
\hline Russell chest seal ${ }^{\mathrm{TM}}$ & 20 & 20 & 20 & 20 & 20 & 20 & 20 & 20 & 20 \\
\hline FAST Breathe Thoracic seal® & - & 60 & 60 & 55 & - & - & - & - & 22 \\
\hline HyFin Vent@ & - & 25 & 60 & 60 & - & - & - & - & 18 \\
\hline SAM chest seal with valve $\AA$ & - & 20 & 50 & 50 & - & - & 20 & 30 & 21 \\
\hline
\end{tabular}

\begin{tabular}{|c|c|c|c|c|c|c|c|c|c|}
\hline \multirow{2}{*}{$\begin{array}{l}\text { Vertical Pulling (\%) } \\
-19.5 \pm 1.3^{\circ} \mathrm{C} \\
\end{array}$} & \multicolumn{4}{|c|}{ Unshaved skin } & \multicolumn{4}{|c|}{ Shaved skin } & \multirow{2}{*}{$\begin{array}{c}\text { detachment } \\
\text { score }\end{array}$} \\
\hline & $\begin{array}{c}\text { Clean } \\
\text { skin }\end{array}$ & Sand & Blood & $\begin{array}{c}\text { Blood + } \\
\text { Sand }\end{array}$ & Clean skin & Sand & Blood & $\begin{array}{c}\text { Blood + } \\
\text { Sand }\end{array}$ & \\
\hline Bolin chest seal $^{\mathrm{TM}}$ & 55 & & 54 & 45 & 45 & & - & 75 & 46 \\
\hline Russell chest seal ${ }^{\mathrm{TM}}$ & 40 & & - & - & - & & - & - & 7 \\
\hline FAST Breathe Thoracic seal@ & 60 & & 65 & 50 & - & & 35 & - & 35 \\
\hline HyFin Vent ${ }^{\circledR}$ & - & & - & 55 & - & & 45 & 65 & 28 \\
\hline SAM chest seal with valve $\AA$ & - & & - & 50 & 45 & & 30 & 63 & 31 \\
\hline
\end{tabular}

\begin{tabular}{|c|c|c|c|c|c|c|c|c|c|}
\hline \multirow{2}{*}{$\begin{array}{l}\text { Vertical Pulling (\%) } \\
\qquad 71.5 \pm 2.0{ }^{\circ} \mathrm{C}\end{array}$} & \multicolumn{4}{|c|}{ Unshaved skin } & \multicolumn{4}{|c|}{ Shaved skin } & \multirow{2}{*}{$\begin{array}{c}\text { detachment } \\
\text { score }\end{array}$} \\
\hline & $\begin{array}{l}\text { Clean } \\
\text { skin }\end{array}$ & Sand & Blood & $\begin{array}{c}\text { Blood + } \\
\text { Sand }\end{array}$ & Clean skin & Sand & Blood & $\begin{array}{l}\text { Blood + } \\
\text { Sand }\end{array}$ & \\
\hline Bolin chest seal $^{\mathrm{TM}}$ & 50 & & 55 & 58 & 63 & & 70 & 60 & $59 *$ \\
\hline Russell chest seal ${ }^{\mathrm{TM}}$ & - & & - & - & - & & - & - & 0 \\
\hline FAST Breathe Thoracic seal@ & - & & - & 40 & - & & - & - & 7 \\
\hline HyFin Vent ${ }^{\circledR}$ & - & & 60 & 48 & - & & 40 & 38 & 31 \\
\hline SAM chest seal with valve $\AA$ & - & & - & 47 & 52 & & 65 & 45 & 35 \\
\hline
\end{tabular}

Table 3: Vertical pulling results following storage at ambient, $-19.5{ }^{\circ} \mathrm{C}$ and $71.5{ }^{\circ} \mathrm{C}$ temperatures for the 5 vented chest seals tested under various soiled skin conditions. The detachment score is the average of all scores. No detachment (-). $* \mathrm{p}<0.05$. 
TABLES

\begin{tabular}{|c|c|c|c|}
\hline Breaching & \multicolumn{3}{|c|}{ Score (\%) } \\
\hline Temperature & Ambient & $-19.5^{\circ} \mathrm{C}$ & $71.5^{\circ} \mathrm{C}$ \\
\hline Bolin chest seal $^{\mathrm{TM}}$ & 23 & 12 & 10 \\
\hline Russell chest seal ${ }^{\mathrm{TM}}$ & - & - & - \\
\hline FAST Breathe Thoracic seal $\AA$ & 10 & 7 & - \\
HyFin Vent ${ }^{\circledR}$ & 8 & 2 & - \\
SAM chest seal with valve $\AA$ & - & - & - \\
\hline
\end{tabular}

Table 4: Breaching score (complete separation of the seal and skin) at ambient, $-19.5{ }^{\circ} \mathrm{C}$ and $71.5^{\circ} \mathrm{C}$ temperatures for the 5 vented chest seals. Average from various soiled skin conditions. No Breach (-). 


\section{FIGURE}

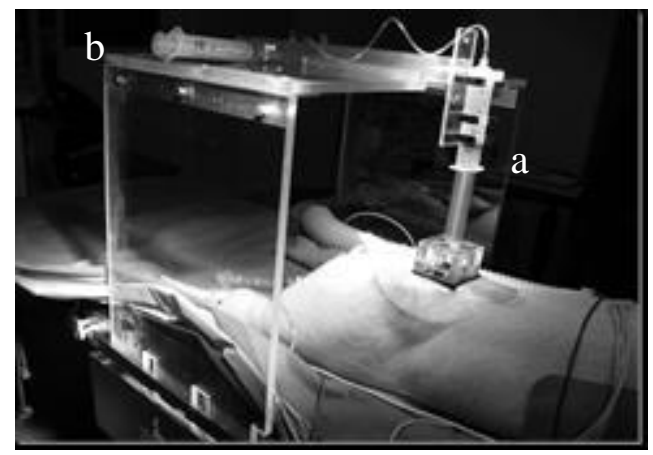

Figure 1: Pulling system that permits lifting the seal upward. a) Syringe system A: this syringe mounted on a Plexiglas block secured to a support base with metal clamps. b) The syringe B connected to system A by pressure tubing. The piston of syringe A moves upwards when syringe $B$ is pulling the liquid in the system. 